\title{
Cyclic and dynamic behaviour of a Canadian sensitive clay
}

\author{
Anna d'Onofrio ${ }^{1}$, Anna Chiaradonna ${ }^{1, *}$, Giuseppe Lanzo $^{2}$, and Mourad Karray ${ }^{3}$ \\ ${ }^{1}$ University of Napoli Federico II, Department of Civil, Architectural an Environmental Engineering, 80125 via Claudio 21, Italy \\ ${ }^{2}$ Sapienza University of Rome, Department of Structural and Geotechnical Engineering, 00197 via Gramsci 53, Italy \\ ${ }^{3}$ Universitè de Sherbrooke, Department of Civil Engineering, 2500, boul. de l'Université Sherbrooke J1K 2R1, Quebec, Canada
}

\begin{abstract}
Clays with higher undisturbed undrained shear strengths than remoulded strengths are considered sensitive. While the stress-strain behaviour of these clays under monotonic loading condition was widely investigated, few data are available of their behaviour under cyclic and dynamic loading conditions. This paper presents the preliminary results of an experimental program on undisturbed samples of a sensitive clay retrieved at Saint Luc de Vincennes (Quebec). In particular, the paper shows the comparison among the modulus reduction curve, $\mathrm{G}_{/} \mathrm{G}_{0}-\gamma$ and the damping ratio variation with shear strain, $\mathrm{D}-\gamma$ measured using different devices, trying to highlight the main factors influencing the observed behaviour, including sample disturbance and storing method. The tests were carried out using one torsional shear and two different cyclic simple shear devices capable of investigating from small to large shear strains. The tests were carried out by three different laboratories at the Université de Sherbrooke, Canada, the University of Naples Federico II and the Sapienza University of Rome, Italy. Oedometric tests also performed by the three different research teams indicate that the clay samples were carefully shipped and stored, and the soil specimens were accurately prepared. Some differences were observed in the $\mathrm{G}_{\mathrm{G}}(\gamma)$ and $\mathrm{D}(\gamma)$ curves obtained by different tests, some of them ascribed to the intrinsic anisotropy of the investigated clay.
\end{abstract}

\section{Introduction}

Clays with higher undisturbed undrained shear strengths than remoulded strengths are considered sensitive. Sensitive clays lose their shear strength under cyclic loading. This strength deterioration due to cyclic loading can be considered one of the causes of several important documented landslides triggered either by pile driving [1], earthquakes [2], [3] or rock blasting [4]. Most of them occurred in Eastern Canada, where extensive and densely populated areas are covered by recent soft and sensitive fine grained sediments.

While the stress-strain behaviour of these clays under monotonic loading condition was widely investigated [5], [6], few data are available on their behaviour under cyclic and dynamic loading conditions [7], [8]. This paper presents some preliminary results of an experimental programme on undisturbed samples of a sensitive clay retrieved at Saint Luc de Vincennes (Quebec) aimed at investigating its cyclic undrained behaviour from small strains to failure. The tests have been carried out by three different laboratories at the Université de Sherbrooke, Canada, the University of Naples Federico II and the Sapienza University of Rome, Italy, with the aim of highlighting the different factors influencing the normalized modulus reduction curve, $\mathrm{G} / \mathrm{G}_{0}-\gamma$, and the damping ratio variation with shear strain, $\mathrm{D}-\gamma$.

\section{Experimental program}

The clay tested in this study was provided from the SaintLuc-de-Vincennes site where a major landslide occurred on the night of Wednesday to Thursday, 10 of November 2016 at rank Saint-Joseph. Saint-Luc-de-Vincennes is a municipality of Quebec located in the regional county municipality of Chenaux, in the administrative region of Mauricie (Quebec, Canada). The site is characterized by a sensitive clay deposit about $70 \mathrm{~m}$ thick; the sensitivity ranges between 40 and 50 in the first $12 \mathrm{~m}$ and becomes lower (25-30) at greater depth. The plasticity index varies between $20-40 \%$. The OCR is generally lower than 2 . The undrained shear resistance increases slowly from $20 \mathrm{kPa}$ to $27 \mathrm{kPa}$ up to $14.5 \mathrm{~m}$ and then sharply increases.

Undisturbed samples were retrieved between 13 and $16 \mathrm{~m}$ depth from the ground surface with a Shelby sampler. The Shelby samples were cut in 5 parts, each part was covered by wax, stored into an airtight case and shipped to the Italian laboratories.

The tested soil is a silty clay with a clay fraction of about $72 \%$, as shown in Figure 1. The main physical properties of the material are summarized in Table 1.

\footnotetext{
* Corresponding author: anna.chiaradonna@unina.it
} 
Table 1. Physical properties of Saint-Luc de Vincennes.

\begin{tabular}{|c|c|c|c|c|}
\hline Soil & Gs & CF (\%) & $\mathrm{w}_{\mathrm{L}}(\%)$ & $\mathrm{I}_{\mathrm{p}}(\%)$ \\
\hline $\begin{array}{c}\text { St-Luc de } \\
\text { Vincennes }\end{array}$ & 2.74 & 72 & 49.2 & 29.4 \\
\hline
\end{tabular}

St-Luc de Vincennes

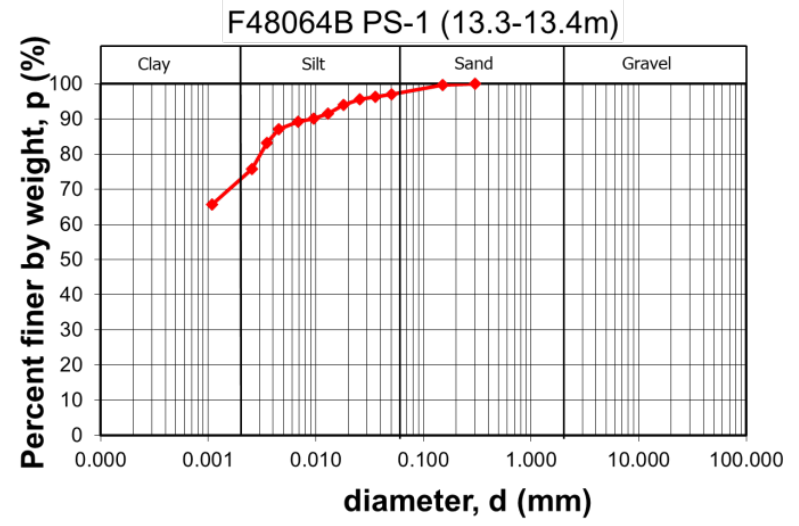

Fig. 1. Grain size distribution of the tested soil.

Oedometric tests allowed to quantify the degree of disturbance and the effect of transportation on the quality of the clay samples. Resonant column (RC) and torsional shear (TS) tests were then carried out at the geotechnical laboratory of University of Naples Federico II (Unina), double specimen direct simple shear (DSDSS) tests were carried out at the geotechnical laboratory of Sapienza University of Rome (UniRoma) and finally triaxial simple shear (TxSS) tests were performed at the geotechnical laboratory of the Sherbrooke University (UniSherbrooke).

All the specimens were first consolidated to the in-situ stress state. To this aim an initial vertical confining pressure equal to $80 \mathrm{kPa}$ was applied in DSDSS and TxSS tests, whereas a mean confining pressure of $60 \mathrm{kPa}$ was imposed in RC and TS tests, assuming a coefficient of pressure at rest, $\mathrm{k}_{0}$, equal to 0.6 . A synthesis of the main characteristics of the cyclic tests carried out at different laboratories is shown in Table 2.

Table 2. Main characteristics of the laboratory tests.

\begin{tabular}{|c|c|c|c|c|}
\hline Test type & $\begin{array}{c}\text { Confinin } \\
\text { g stress } \\
(\mathrm{kPa})\end{array}$ & $\begin{array}{c}\text { Applied } \\
\text { frequency } \\
(\mathrm{Hz})\end{array}$ & $\begin{array}{c}\text { Stress } \\
\text { controlled }\end{array}$ & $\begin{array}{c}\text { Strain } \\
\text { controlled }\end{array}$ \\
\hline RC1 & 60 & $12-14$ & $\mathrm{X}$ & \\
\hline TS1 & 60 & 0.5 & $\mathrm{X}$ & \\
\hline TS2 & 60 & 0.5 & $\mathrm{X}$ & \\
\hline DSDSS & 80 & $0.1-0.3$ & & $\mathrm{X}$ \\
\hline TxSS1 & 80 & 1 & & $\mathrm{X}$ \\
\hline TxSS2 & 80 & 1 & & $\mathrm{X}$ \\
\hline
\end{tabular}

\subsection{Resonant column and torsional shear tests}

Tests were carried out by using a prototype of resonant column/torsional shear device (THOR), as shown in Figure 2. The equipment, originally developed at the
University of Naples Federico II, is extensively described by [9].

Each specimen $(36 \mathrm{~mm} \times 72 \mathrm{~mm})$ was first isotropically consolidated at the in situ stress, then the non-linear behaviour of the soil was investigated by performing a sequence of undrained resonant column (RC1) and torsional shear (TS1) tests at increasing strain level. By applying this procedure, the soil specimen was subjected to a very high number of cycles that could induce some stiffness degradation in sensitive clay. To verify this occurrence a second specimen was investigated only through torsional shear tests (TS2) in order to limit the influence of repeated cycles on the soil response.
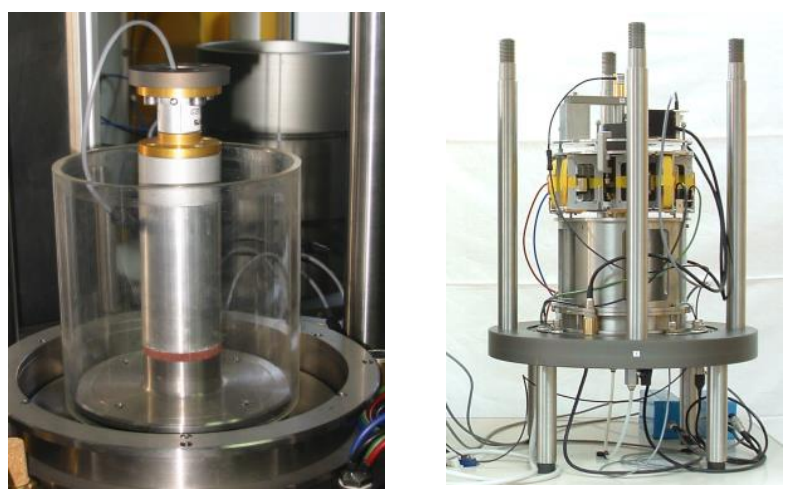

Fig. 2. Resonant column/torsional shear device (THOR).

\subsection{Double specimen direct simple shear tests}

The DSDSS (Double Specimen Direct Simple Shear) tests have been conducted in a device built at the Soil Dynamics Laboratory of the Sapienza University of Rome [10]. This type of apparatus, originally developed by Doroudian and Vucetic [11], is capable of investigating, in a single test, the cyclic properties from very small to very large strains. Its configuration, capabilities and limitations are fully described in [10].

The peculiarity of the DSDSS device is that two parallel specimens are sheared simultaneously, instead of just one. The specimens are of the Norwegian Geotechnical Institute (NGI) type [5], i.e. they have cylindrical shape (66 $\mathrm{mm}$ in diameter and $20 \mathrm{~mm}$ high) and they are confined by a wire-reinforced rubber membrane that prevent lateral deformations during the application of horizontal loads. Such a dual configuration, together with very stiff components of the device, allows to adequately reduce mechanical compliance of the apparatus and to avoid problems which are otherwise typical of a standard NGI direct simple shear device and that preclude the possibility to investigate cyclic properties of soils at small strains.

The tests are carried out on fully saturated cylindrical specimens consolidated under anisotropic conditions. After the consolidation stage, the specimens were subjected to several consecutive cyclic strain-controlled tests with cyclic shear strain amplitude equals to $\gamma_{c}$. The cyclic shear strain amplitude $\gamma_{c}$ varied from about $0.0004 \%$ to $1.1 \%$. Frequency of cyclic loading ranged between approximately 0.1 and $0.3 \mathrm{~Hz}$. 


\subsection{Triaxial simple shear test}

The direct simple shear (DSS) apparatuses are generally desirable as they can better approximate the stress-strain state to which soils experience in the field. The simple shear deformation in the DSS test is consistent with earthquake ground deformation. However, several researchers have criticized these devices as they only measure the total vertical normal stress during shearing ([12]; [13]). A number of authors (e.g., [14]; [15]) have developed DSS apparatuses which surround the test specimen with an array of load cells to measure the complete state of stress around the specimen. Others researchers indirectly monitored the change in the pore pressure induced in the soil samples by the passage of seismic waves through a constant volume test by adjusting the applied vertical stress during the test. Few authors (e.g., [16], 1979) placed the DSS soil specimen in a pressure cell. Thus, back pressure can be applied to ensure full saturation of the specimen and the pore water pressure can be directly measured in an undrained shear test. In fact, most of the developed apparatuses are very complex and the extent of their use does not exceed research purposes, In addition, the DSS tests can be conducted only under a uniform cyclic loading, which does not seem to represent the reality. In an attempt to minimize the difficulties and the errors associated with the DSS as well as other conventional techniques, and to obtain high quality experimental test data on the static and dynamic characteristics of soil samples, a user-friendly seismic simulator was developed by the Institut de Recherche d'Hydro-Québec (IREQ) in collaboration with the Geotechnical laboratory at the Universite de Sherbrooke (UdeS) (Chekired et al. 2015).

This simulator allows for a simple shear test in a closed cell (TxSS) and helps to replicate field loading conditions as closely as possible by being able to apply seismic displacement (real seismograms) while applying vertical loads simultaneously. The cyclic triaxial simple shear test (TxSS) apparatus [17], used in this study, was designed and manufactured to permit the application of monotonic loading as well as both regular and irregular cyclic shear stresses or strains to soil materials. The general assembly of the TxSS apparatus in shown in Figure 3. The TxSS device was designed to test cylindrical soil specimens with a diameter varying between 63 (Shelby tube) and $80 \mathrm{~mm}$ and varying heights in a triaxial cell. Unlike the DSS apparatus that requires the soil specimen to be prepared in stacks of annular plates/rings or reinforced membrane, the TxSS specimen is installed between relatively rigid bottom and top caps and is typically confined by a rubber membrane. The bottom and top caps that contain fine porous stones provide a "frictional" surface while allowing for drainage into the porous stones. In the case of clay samples the porous stones are provided with small spikes to prevent slippage of the soil. The clay specimen is consolidated to a desirable confining stress, and then simple shear stress or strain is presumed to be imposed by displacing the specimen's top cap using the shear ram shown in Fig. 3, which is connected to a shaker with linear shaft motor mounted on a horizontal table. The motor is characterized by its high-thrust capability (up to $100,000 \mathrm{~N}$ ), its high precision $(0.07 \mathrm{~nm})$, and its very low speed fluctuation $( \pm$ $0.006 \%$ at $100 \mathrm{~mm} / \mathrm{s})$. It is very quit due to the absence of friction (non-contact operation is also possible using air slider). The max and min speed drive are $10 \mathrm{~m} / \mathrm{s}$ and $\mu 8$ $\mathrm{m} / \mathrm{s}$, respectively. A computer-automated feedback-loopcontrolled system provides an excellent control of stresses and strains. The TxSS system permits testing soil samples with different heights under either drained or undrained conditions as well as the direct measurement of the pore water pressure generation during the undrained shear test. It also provides the opportunity for geotechnical engineers and researchers to test undisturbed and reconstituted soil samples under either isotropic or anisotropic loading conditions.

In this study, the clay specimens was cyclically sheared under strain-controlled condition with a maximum shear strain of $2 \%$ and a frequency of $1 \mathrm{~Hz}$. The samples tested had a diameter of $63 \mathrm{~mm}$ and a height between 22 and $23 \mathrm{~mm}$. It is important to note that the TxSS tests were achieved in fully saturated undrained conditions $(\mathrm{B}>0.97)$ without any restriction.

An example of loops are presented in Fig. 4. Each loop in is an average of 6 cycles applied to the specimen at the same maximum strain amplitude. As shown in Fig. 4, a gradual increase in the loop area is observed with the increase in the applied cyclic shear strain. The secant shear modulus in Fig. 4 is defined as $G=\tau_{c} / \gamma_{c}$, where $\tau_{\mathrm{c}}$ is the cyclic stress amplitude corresponding to the strain amplitude $\gamma_{\mathrm{c}}$.

The experimental loops are compared to numerical SIG4 model, available in the library of the computer code FLAC 2D [18].

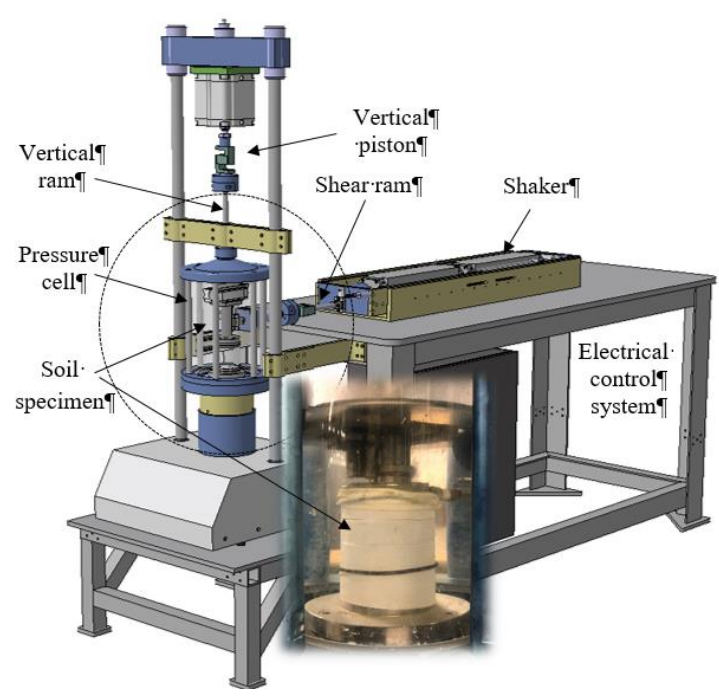

Fig. 3. Schematic sketch of the Triaxial Simple Shear (TxSS) apparatus. 

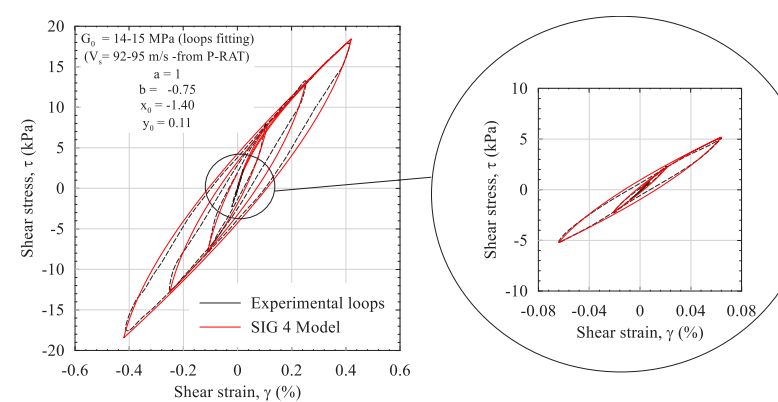

Fig. 4. Typical loop obtained using TxSS for a frequency of cyclic loading of $1 \mathrm{~Hz}$. Loops are average of 6 cycles.

The area enclosed in the hysteresis loop (A) is used to define the damping ratio as:

$$
D=\frac{1}{2 \pi} \frac{A}{G \gamma_{c}^{2}}
$$

It is important to note the $\mathrm{G}_{0}\left(\rho \mathrm{V}_{\mathrm{s}}^{2}\right)$ was determined using the piezo-electric ring actuator technique (P-RAT) developed at Université de Sherbrooke. More details about the P-RAT technique are reported in[19].

\section{Laboratory test results}

An oedometric test was preliminary carried out at each laboratory to verify if storage and shipping could have induced any disturbance to the clay samples.

Fig. 5 compares the oedometric curves obtained by the three research teams. The curves are very similar confirming that the clay samples do not suffer any trouble due to the transport; the initial void ratio is slightly variable ranging between 1.80 and 1.73 . The same vertical effective yield stress is detected on the three curves (135$140 \mathrm{kPa})$.

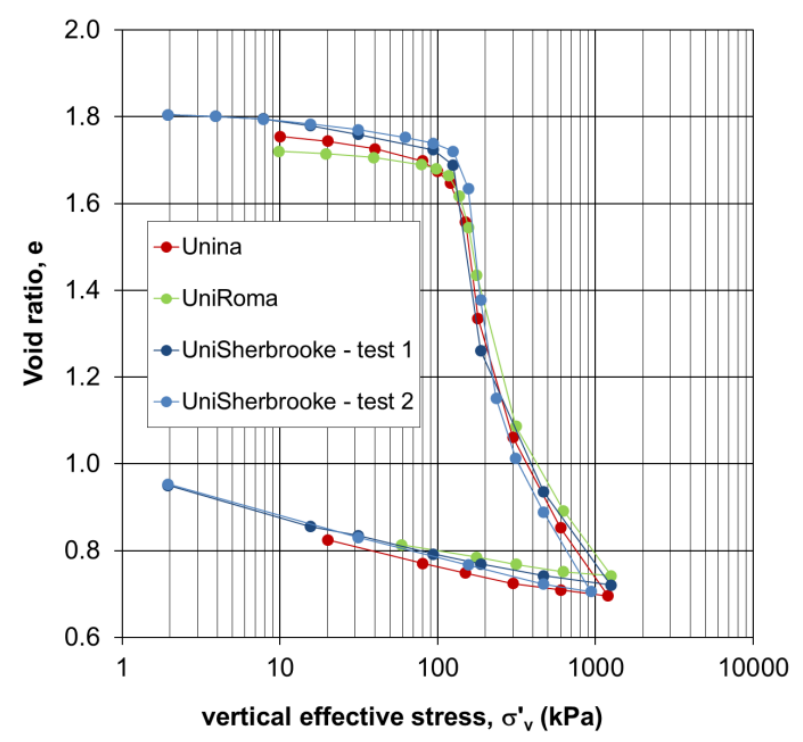

Fig. 5. Comparison of the oedometric curves.

\subsection{Cyclic tests results}

The initial shear modulus measured by adopting the three different devices is reported in Fig. 6 together with the initial damping ratio as a function of the applied confining stress.

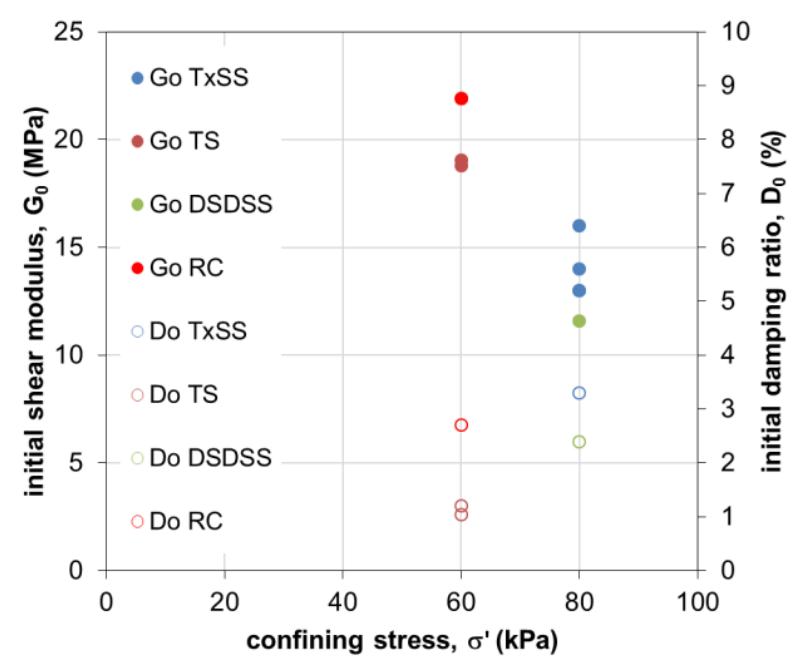

Fig.6. Comparison among initial shear modulus and damping ratio measured with the different devices.

The initial shear modulus measured with both resonant column and torsional shear tests is systematically higher than that measured by DSDSS and TxSS apparatuses. It is worth highlight that the initial shear modulus in TxSS apparatus is obtained by Piezo-electric ring actuator ( $\mathrm{P}$ RAT). The value of $\mathrm{G}_{0}$ in vertical direction (SV) was evaluated at about $15 \mathrm{MPa}$ in this study. On the other hand, the initial damping ratio measured with RCTS test is similar to that measured by DSDSS but systematically lower than that measured by TxSS tests. It is worth noting that the data shown in Fig. 6 are not obtained at the same strain level, since the RCTS device reliably measures strains lower than $10^{-4} \%$ whereas this in not the case of both simple shear apparatuses.

Differences observed between data measured in resonant column (RC) and torsional shear (TS) tests is due to the different loading frequency applied in the two tests that can affect significantly the initial shear modulus and damping ratio [20].

The results were also compared in Fig. 7 in terms of normalised shear modulus and damping ratio curves.

The normalized shear modulus curves from RC, TS and DSDSS tests highlights a linear threshold strain around $0.03 \%$. The related modulus reduction curves seem not to be affected by both frequency content of the applied load and number of cycles. In fact, the curves overlap notwithstanding the different imposed frequency (see Table 2) and the high number of cycles applied in the resonant column tests. A less linear and more dissipative behaviour is observed in the TxSS test: the linear threshold in this case is equal to $0.007 \%$. A sharp reduction of shear modulus is observed at higher strains corresponding to a significant damping increase. 


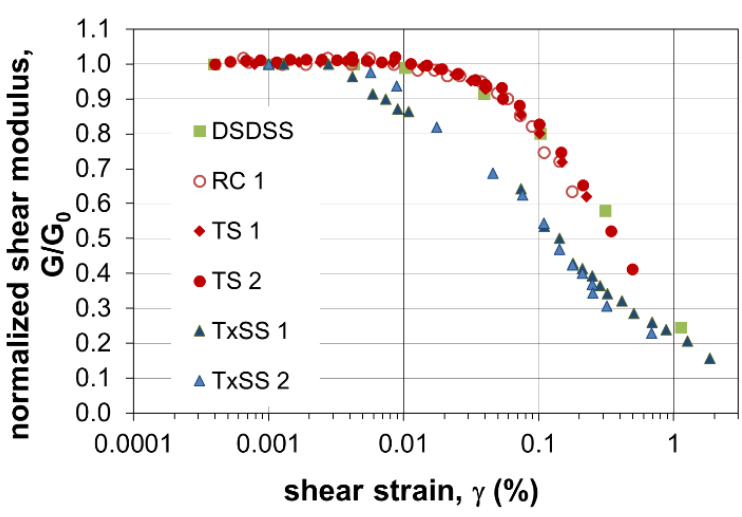

(a)

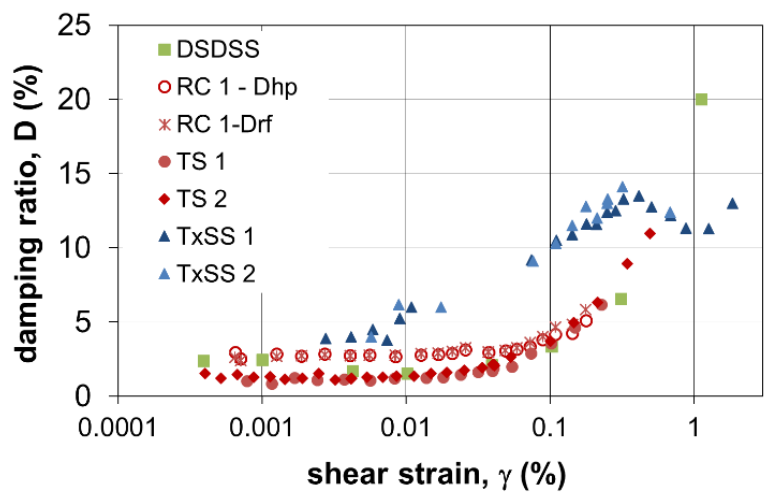

(b)

Fig. 7. Comparison of the $G / G_{0}-\gamma$ (a) and $D-\gamma$ (b) curves.

This effect can be better highlighted comparing the cyclic loops recorded at comparable strain level, adopting the three different devices (Fig. 8).

As a matter of fact, the cyclic loops measured by both TS and DSDSS tests, even if referring to slightly different strain level, show a similar dissipative behaviour. On the other hand, the cyclic stress strain loop measured at similar strain level by TxSS device is characterised by a higher dissipated energy. As shown by the results reported in Fig. $7 \mathrm{a}$ and $7 \mathrm{~b}$, this significant difference in energy dissipation characterizes the soil response in TxSS test on the whole investigated strain range. Investigations are still going on to better understand the reasons of this enhanced non linearity measured in TxSS tests.

\section{Conclusions}

The preliminary results of a joint investigation on the cyclic behaviour of a Canadian sensitive clay are presented. The study is aimed at highlighting the main factors affecting the experimental undrained behaviour of this peculiar clays. Cyclic and dynamic tests with three different devices have been carried out. The results presented here are aimed at preliminary verifying the comparability of the measurements obtained by the different devices.

The oedometric curves obtained by the three different research teams indicate that the samples used can be qualified as undisturbed samples. The similarity among the three oedometric curves indicates also that the clay samples were carefully shipped and stored, and the soil specimens were accurately prepared by the different groups.

The initial shear modulus measured in resonant column and torsional shear tests is higher than that measured by simple shear devices. This is probably due to the higher resolution of stress and strain measurement obtained by the torsional shear apparatus, if compared to the simple shear ones.

Differences between the values of initial shear modulus measured in RCTS and TxSS results can also be ascribed to the intrinsic anisotropy of the tested clay.

As a matter of fact, the initial shear modulus measured by Piezo-electric ring actuator is obtained from the shear velocity of waves polarized in the vertical direction, while that measured in RC test is inferred from the shear velocity of $\mathrm{SH}$ waves. It can be expected that the $\mathrm{G}_{0}$ in the horizontal direction, is different from $\mathrm{G}_{0}$ in the vertical direction due to the anisotropy of the clay.

Furthermore, some differences were observed in the $\mathrm{G} / \mathrm{G}_{0}(\gamma)$ and $\mathrm{D}(\gamma)$ curves obtained by TxSS device if compared to those measured by TS and DSDSS apparatuses. Further investigation is in progress to resolve this issue.

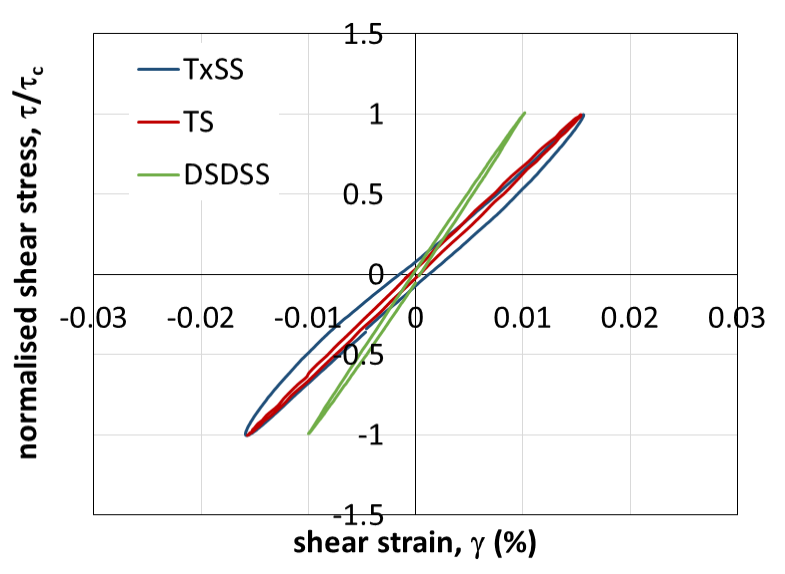

(a)

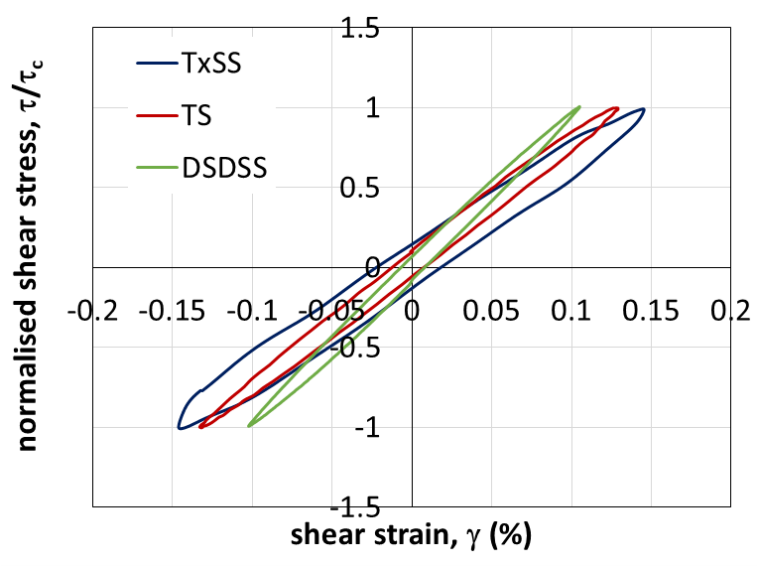

(b)

Fig. 8. Comparison among stress-strain loops obtained by different devices at (a) $\gamma=0.015 \%$ and (b) $\gamma=0.15 \%$. Based on the preliminary results, it seems that neither frequency nor the number of cycles affect the cyclic 
behaviour of the investigated clay, at least in the analysed strain range, although it was expected based on the few results available in literature [21]. Further tests are now in progress on undisturbed clay and some more tests will be carried out on reconstituted samples in order to quantify the sensitivity of the studied clay and to evidence the effect of structure on its cyclic behaviour.

\section{References}

1. G. Burckhardt, Étude en laboratoire du comportement de l'argile de Rigaud sous sollicitations monotones et cycliques. Mémoire de maîtrise (M.Sc.), Département de génie civil, Université Laval (2004)

2. G. Lefebvre, D. LeBoeuf, P. Hornych, L. Tanguay, Slope failures associated the 1988 Saguenay earthquake, Quebec, Canada. Can. Geot. J. 29(1): 117-130 (1992)

3. D. LeBoeuf, A. Bustamante, A. Effects of seismic loadings on the stability of slopes in sensitive clays. Communication presented at the 1st Int. Workshop on Landslides in Sensitive Clays, Quebec City (2013)

4. S. Bouchard, S. Leroueil, D. LeBoeuf, Analysis of a blast loading near sensitive clay slope in La Romaine village, Qc. Proc. of the 68th Can. Geotech. Conf., Quebec City, Canada (2015)

5. L. Bjerrum, A. Landva Direct simple-shear test on a Norwegian quick clay. Géotechnique, 16(1): 1-20. doi:10.1680/geot.1966.16.1.1 (1966)

6. F. Burnotte, G. Lefebvre, G. Grondin, A case record of electroosmotic consolidation of soft clay with improved soil-electrode contact. Can. Geotech. J. 41: 1038-1053 (2004)

7. M. Karray, M.N. Hussein, M. Chekired, Y. Ethier, Small strain stiffness and stiffness degradation curve of sensitive Champlain clay. GeoVancouver (2016)

8. A. Chehat, M.N. Hussein, M. Abdelazize, M. Chekired, Z. Harichane, M. Karray Can. Geotech. J. (2018) https://doi.org/10.1139/cgj-2017-0732

9. A. d'Onofrio, F. Silvestri, F. Vinale, A New Torsional Shear Device. Geotech. Testing J. 22(2): 107-117 (1999)

10. B. D’Elia, G. Lanzo, A. Pagliaroli, Small-strain stiffness and damping of soils in a direct simple shear device, Pacific Conf. on Earth. Eng., Christchurch, New Zealand (2003)

11. M. Doroudian, M. Vucetic, A direct Simple Shear Device for Measuring Small-Strain Behavior. Geotechnical Testing Journal, 18(1): 69-85 (1995)

12. N. Boylan, M. Long, Development of a direct simple shear apparatus for peat soils. Geotech. Testing J., 32(2): 126- 138. doi:10.1520/GTJ101703. (2009)

13. M. N. Hussien, M. Karray, M. Chekired, Evaluation of DSS test results on granular soils based on TxSS results. 68th Canadian Geotechnical International Conference, Quebec, Canada (2015)
14. M. Budhu, Simple Shear Deformation of Sands, Ph.D. thesis, University of Cambridge (1979)

15. D. W. Airey, Clays in Circular Simple Shear Apparatus, Ph.D. thesis, University of Cambridge (1984)

16. E. Franke, M. Kiekbusch, B. Schuppener, A New Direct Simple Shear Device, Geotech. Testing J. 2(4):190-199 (1979)

17. M. Chekired, R. Lemire, M. Karray, M.N. Hussien, Experiment setup for simple shear tests in a triaxial cell: TxSS. 68th Canadian Geotechnical International Conference, Quebec, Canada

18. Itasca. FLAC, Fast Lagrangian Analysis of Continua, version 8.0 Computer Program and the User's Guide, Itasca Consulting Group Inc. (2016)

19. M. Karray, M. Ben Romdhan, M.N. Hussien, Y. Éthier, Measuring shear wave velocity of granular material using the Piezoelectric Ring Actuator Technique (P-RAT). Can. Geotech. J., 52(9): 13021317 (2015)

20. A. d'Onofrio, F. Silvestri, F. Vinale, Strain rate dependent behaviour of a natural stiff clay. Soils and Found., 39: 69-82, ISSN: 0038-0806 (1999)

21. K. K. Rasmussen, An investigation of monotonic and cyclic behaviour of Leda Clay, Master Thesis of Engineering Science, The University of Western Ontario, Canada 